University of Nebraska - Lincoln

DigitalCommons@University of Nebraska - Lincoln

April 1987

\title{
Enhanced magnetism in amorphous Fe-based alloys
}

Sy_Hwang Liou

University of Nebraska-Lincoln, sliou@unl.edu

S.H. Ge

The Johns Hopkins University, Baltimore, Maryland

J.N. Taylor

The Johns Hopkins University, Baltimore, Maryland

C.L. Chien

The Johns Hopkins University, Baltimore, Maryland

Follow this and additional works at: https://digitalcommons.unl.edu/physicsliou

Part of the Physics Commons

Liou, Sy_Hwang; Ge, S.H.; Taylor, J.N.; and Chien, C.L., "Enhanced magnetism in amorphous Fe-based alloys" (1987). Si-Hwang Liou Publications. 11.

https://digitalcommons.unl.edu/physicsliou/11

This Article is brought to you for free and open access by the Research Papers in Physics and Astronomy at DigitalCommons@University of Nebraska - Lincoln. It has been accepted for inclusion in Si-Hwang Liou Publications by an authorized administrator of DigitalCommons@University of Nebraska - Lincoln. 


\title{
Enhanced magnetism in amorphous Fabased alloys
}

\author{
S. H. Liou, S. H. Ge, al J. N. Taytor, and C. L. Chien \\ Physics and Astronomy Department, The Johns Hopkins University, Baltimore, Maryland 21218
}

Systematic investigations of binary amorphous $\mathrm{Fe}-\mathrm{T}$ alloys $(\mathrm{T}=$ an early transition-metal elements $\mathrm{Ti}, \mathrm{Zr}, \mathrm{Nb}, \mathrm{Hf}, \mathrm{Ta} .$. ) over wide composition ranges reveal depressed magnetic properties with anomalously low magnetic ordering temperature and magnetization. We show in this work, via a prototype amorphous $\mathrm{Fe}_{70} \mathrm{~T}_{30}$ alloy, the substitution of $\mathrm{Fe}$ by $\mathrm{Co}, \mathrm{Ni}$, or $\mathrm{Cu}$ greatly enhances the magnetic ordering temperature and the magnetization. Our results indicate that this is primarily caused by the increased $\mathrm{Fe}$ moment upon alloying.

\section{INTPODUCTION}

In all binary amorphous $\mathrm{Fe}_{y} \mathrm{Ti}_{100}$ alloys $(\mathrm{T}=$ an early transition metal, $\mathrm{T}, \mathrm{Zr}, \mathrm{Nb}, \mathrm{HE}, \mathrm{Ta}, \ldots$ etc.) over wide composition ranges, anomalously low magnetic ordering temperature $\left(T_{c}\right)$ and magnetization have been observed. ${ }^{1-6}$ In fact, regardless of the $\mathrm{Fe}$ content, the $T_{c}$ 's of all of these samples are below room temperature, unsuitable for most magnetic applications. For example, the $T_{c}$ of $a-\mathrm{Fe}_{70} \mathrm{~T}_{39}$ is only $215 \mathrm{~K}$, despite its high Fe concentration. In many cases, these alloys do not even exhibit simple ferromagnetic characteristics. The depressed magnetism in these binary alloys is thought to be caused by the drastic reduction of the $\mathrm{Fe}$ moment. In this work, we show that both the magnetization and $T_{c}$ can be greatly enhanced by substituting various amounts of $\mathrm{Co}, \mathrm{Ni}$, or $\mathrm{Cu}$ for $\mathrm{Fe}$ in a prototype alloy of $a \cdot \mathrm{Fe}_{70} \mathrm{Ti}_{30}$

The elements of $\mathrm{Co}, \mathrm{Ni}$, and $\mathrm{Cu}$ are used because of their distinctively different magnetic characteristics. In amorphous alloys, Co retains its high moment, Ni often exhibits only a very small monent, whereas $\mathrm{Cu}$ is nominally nonmagnetic. On the other hand, the atomic sizes of $\mathrm{Co}, \mathrm{Ni}, \mathrm{Cu}$, and Fe are nearly identical (within $1 \%$ ). One therefore expects no appreciable changes in the structure in the amorphous alloys when different alloying element is used.

The sample of $a-\mathrm{Fe}_{70} \mathrm{Ti}_{30}$ has been chosen for the following reasons. Earlier we found ${ }^{2}$ that amcrphous $\mathrm{Fe}_{x} \mathrm{Ti}_{100 \ldots x}$ alloys exist in the composition range of $30 \leqslant x \leqslant 80$. The composition of $x=70$ is sufficiently far from the boundary composition that the crystallization temperature is high and re. mains so upon further alloying. In $Q-\mathrm{Fe}_{x} \mathrm{~T}_{100-x}$ both $T_{c}$ and the Fe moment increase with $x$. Relatively high values have already been realized in $a-\mathrm{Fe}_{70} \mathrm{Ti}_{30}$.

\section{EXPERIKENT}

Samples of amorphous $\mathrm{Fe}_{x}(\mathrm{Co}, \mathrm{Ni}, \mathrm{Cu})_{70-x} \mathrm{Ti}_{30}$ alloys with $x$ varying from 0 to 70 have been prepared by a high-rate magnetron sputtering technique with film thick. ness of $6-20 \mu \mathrm{m}$. The amorphous nature of the samples have been confirmed by an energy dispersive $x$-ray diffraction me-

\footnotetext{
a) Permanent address: Physics Department, Lanzhou University, Lanzhou, China.
}

thod. Magnetization of the alloys has been studied by a SQUID magnetometer in the field range $0-50 \mathrm{kG}$. The mag netic ordering temperature has been determined under zero field by a zero-velocity thermal scan method using ${ }^{57} \mathrm{Fe}$ Mössbauer spectroscopy. The effective magnetic hyperfine fields have been obtained from the analyses of the Mössbauer spectra.

\section{RESULTS AND DISCUSSIONS}

Some representations of magnetization curves of amor. phous $\mathrm{Fe}_{x}(\mathrm{Co}, \mathrm{Ni} \text {, or } \mathrm{Cl})_{70-x} \mathrm{Ti}_{30}$ alloys are shown in Fig. 1. These samples are clearly ferromagnetic, for the magnetization can be easily saturated. Within each series, all $\mathrm{Fe}_{x} \mathrm{Ni}_{70-x} \mathrm{Ti}_{30}$ and $\mathrm{Fe}_{x} \mathrm{CO}_{70-x} \mathrm{Ti}_{30}$ samples show ferromagnetic characteristics. In $\mathrm{Fe}_{x} \mathrm{Cu}_{70-x} \mathrm{Ti}_{30}$, most samples are ferromagnetic except those with low iron concentration which show paramagnetic or spin glass behavior. The spontaneous magnetization $\left(M_{3}\right)$ of each sample is determined by extrapolating the magnetization curve to zero magnetic field. The variation of $M_{s}$ with iron concentration of amorphous $\mathrm{Fe}(\mathrm{Co}, \mathrm{Ni}$, or $\mathrm{Cu})$ - $\mathrm{Ti}$ alloys are shown in Fig. 2 . It is noted that $M_{s}$ increases when $\mathrm{Co}$ or $\mathrm{Ni}$ is first introduced to

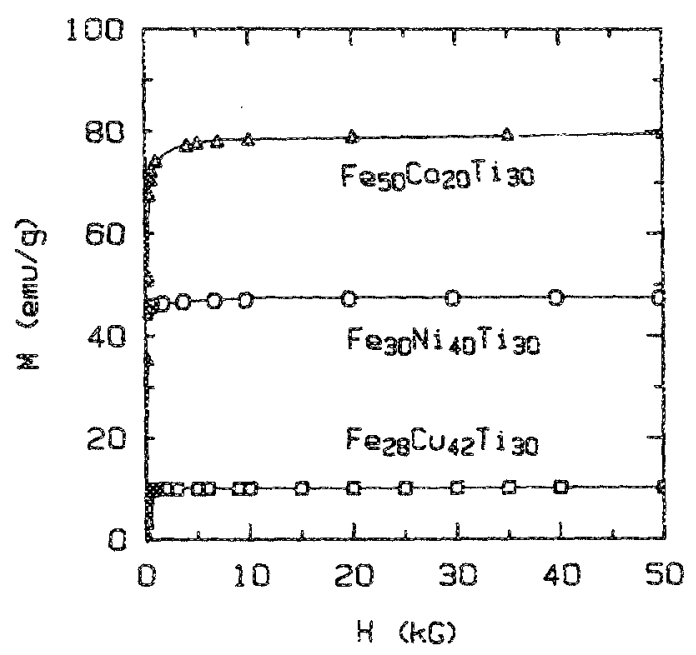

FIG. 1. Magnetization in emu/g of amorphous $\mathrm{Fe}_{50} \mathrm{Co}_{20} \mathrm{Ti}_{30}, \mathrm{Fe}_{30} \mathrm{Ni}_{40} \mathrm{Ti}_{30}$, and $\mathrm{Fe}_{28} \mathrm{Cu}_{43} \mathrm{Ti}_{30}$ at $6 \mathrm{~K}$ as a function of held. 


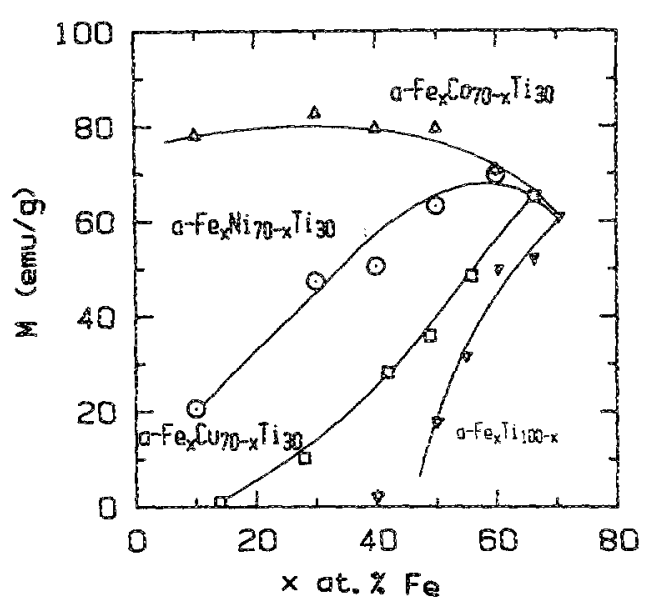

FIG. 2. Spontaneous magnetization measured at $6 \mathrm{~K}$ of amorphous $\mathrm{Fe}_{x} \mathrm{Co}_{70-x} \mathrm{Ti}_{30}, \mathrm{Fe}_{x} \mathrm{Ni}_{70-x} \mathrm{Ti}_{30}$, and $\mathrm{Fe}_{x} \mathrm{Cu}_{70-x} \mathrm{Ti}_{30}$ as a function of $\mathrm{Fe}$ content.

replace $F e$. Beyond that, distinctively different behaviors are observed. In $\mathrm{Fe}_{x} \mathrm{Ni}_{70-x} \mathrm{Ti}_{30}$, the increase of $M_{5}$ levels off at $\mathrm{Fe}_{50} \mathrm{Co}_{20} \mathrm{Ti}_{30}$. Further replacement of $\mathrm{Fe}$ by $\mathrm{Co}$ does not noticeably affect $M_{s}$. In $\mathrm{Fe}_{x} \mathrm{Ni}_{70 \ldots x} \mathrm{Ti}_{30}$, beyond the initial rise, $M_{s}$ decreases monotonically towards the Ni-rich end. Since Ni has a moment less than that of $\mathrm{Fe}$, the initial rise in $M_{s}$ is
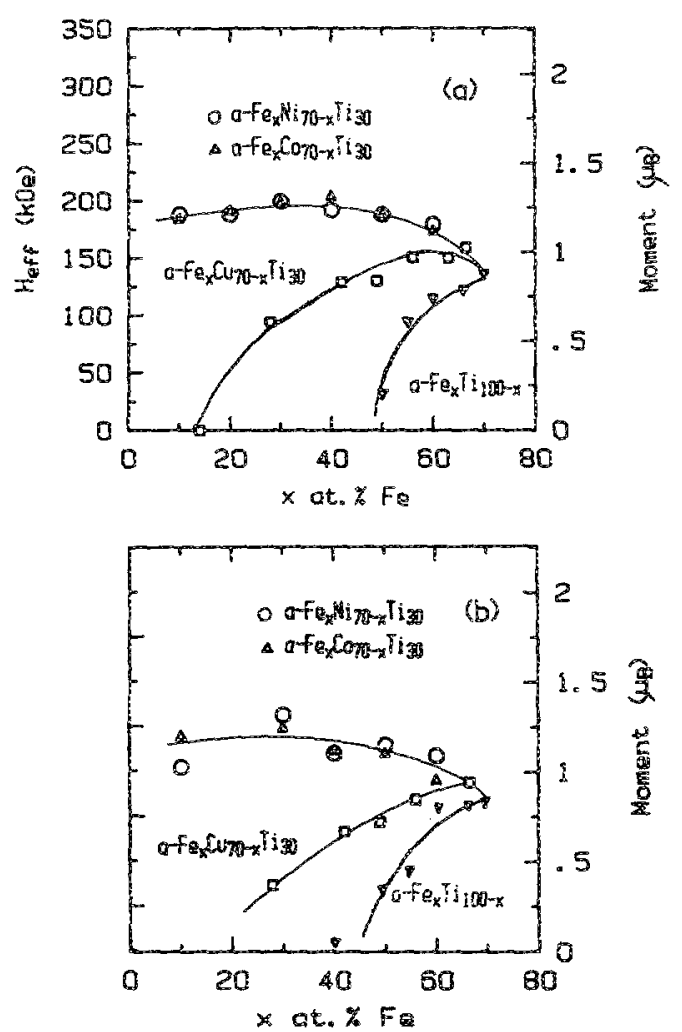

FIG. 3. (a) Magnetic hyperfine field ( $H_{\text {eff }}$ ) at the Fe sites measured at 4.2 $\mathrm{K}$ of amorphous $\mathrm{Fe}_{x} \mathrm{CO}_{70-x} \mathrm{Ti}_{30}, \mathrm{Fe}_{x} \mathrm{Ni}_{70-x} \mathrm{Ti}_{30}$, and $\mathrm{Fe}_{x} \mathrm{Cu}_{70-x} \mathrm{Ti}_{30}$ as a function of $\mathrm{Fe}$ content. For comparison, the resuits for amorphous $\mathrm{Fe}_{x} \mathrm{Ti}_{100-x}$ are also shown. By using a conversion factor of $150 \mathrm{kOe} / \mu_{B}$, the values of $\mathrm{Fe}$ moment are obtained. (b) Fe moment of amorphous $\mathrm{Fe}_{x} \mathrm{Co}_{70 \ldots} \mathrm{Ti}_{30}, \mathrm{Fe}_{x} \mathrm{Ni}_{70-x} \mathrm{Ti}_{30,}$ and $\mathrm{Fe}_{x} \mathrm{Cu}_{70-x} \mathrm{Ti}_{30}$ as a function of $\mathrm{Fe}$ content. The moments of $\mathrm{Co}, \mathrm{Ni}$, and $\mathrm{Cu}$ are assumed to be $1.17,0.17$, and 0 $\mu_{R}$, respectively.

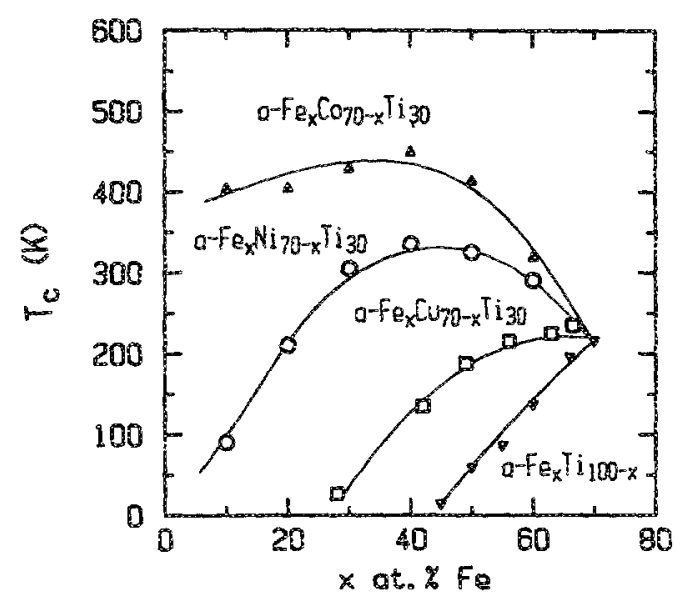

FIG. 4. Magnetic ordering tempezature $\left(T_{c}\right)$ of amorphous $\mathrm{Fe}_{x} \mathrm{CO}_{70-x} \mathrm{Ti}_{30}$, $\mathrm{Fe}_{x} \mathrm{Ni}_{70-x} \mathrm{Ti}_{30}, \mathrm{Fe}_{x} \mathrm{Cu}_{70-x} \mathrm{Ti}_{30}$, and $\mathrm{Fe}_{x} \mathrm{Ti}_{100-x}$ as a function of $\mathrm{Fe}$ content.

due to the enhancenent of the Fe moment. Because both Co and $\mathrm{Fe}$ have sizable magnetic moments in $\mathrm{Fe}-\mathrm{Co}$-Ti alloys, there is relatively little variation of $M_{s}$. In the case of $\mathrm{Fe}-\mathrm{Ni}$ $\mathrm{Ti}$ alloys on the other hand, Ni only has a very small moment, resulting a monotonically decreasing $M_{s}$. In $F e_{x} \mathrm{Cu}_{70-x} \mathrm{Ti}_{30}, \mathrm{Cu}$ is expected to carry no moment. As a consequence, $M_{s}$ decreases monotonically. At about Fe${ }_{15} \mathrm{Cu}_{55} \mathrm{~T}_{30}, M_{s}$ drops to zero and the alloys with lower $\mathrm{Fe}$ content cease to be ferromagnetic.

We have also used the magnetic hyperfine field, measured from ${ }^{57} \mathrm{Fe}$ Mössbauer spectroscopy to obtain information about the Fe magnetic moment. It has been known that the magnetic hyperfine field provides a reasonable measure of the Fe moment. The compositional dependence of the magnetic hyperfine fields $\left(H_{\text {efr }}\right)$ at the Fe sites and the spontaneous magnetization allow the magnetic moments of the constituent elements to be resolved.

First of all, when Ni or Co is first introduced, both $H_{\text {eff }}$ [Fig. 3(a)] and $M_{s}$ (Fig. 2) increase. This further confirms the fact the Fe moment is indeed enhanced. Beyond that, in $\mathrm{Fe}-\mathrm{Co}-\mathrm{T}$ alloys, $H_{\text {ef }}$ and $M_{s}$ remain nearly constant below $x=40$, indicating that the magnetic moments of Fe and Co are approximately the same. In $\mathrm{Fe}-\mathrm{Ni}-\mathrm{Tr}$ alloys, however, $M_{s}$ reduces rapidly with decreasing $x$ as shown in Fig. 2 while $H_{\text {eff }}$ remains nearly unchanged as shown in Fig. 3(a). This indicates Fe retains its moment throughout the composition range, whereas Ni has only a very small moment. In Fe-Cu-Ti alloys, the behaviors of $M_{s}$ and $H_{\text {eff }}$ do not suggest an appreciable $\mathrm{Cu}$ moment, as expected.

in Fig. $3(b)$, we replot the $M_{s}$ values shown in Fig. 2 as magnetic moment per $\mathrm{Fe}$, assuming that $\mathrm{Co}, \mathrm{Ni}$, and $\mathrm{Cu}$ moments are $1.17,0.17$, and $0 \mu_{B}$, respectively. The remarkable similarity between Figs. $3(a)$ and $3(b)$ for all threealloy systems of $\mathrm{Fe}_{x}(\mathrm{Co}, \mathrm{Ni}, \mathrm{Cu})_{70-x} \mathrm{Ti}_{30}$ indicates that the above choices are reasonable. Also shown in Fig. 3(a) are the data ${ }^{2}$ of $\mathrm{Fe}$ moment of $a-\mathrm{Fe}_{x} \mathrm{Ti}_{100-x}$ before the addition of $\mathrm{Co}, \mathrm{Ni}$, or $\mathrm{Cu}$ for comparison. It is then clear, as displayed in Fig. 3(b), that the Fe moment is greatly enhanced by adding $\mathrm{Co}, \mathrm{Ni}$, or $\mathrm{Cu}$ into amorphous $\mathrm{Fe}-\mathrm{Ti}$ alloys. The alloying elements influence the electronic struc- 
ture and, thereby, the formation of the Fe moment. A similarly sharp increase of iron moment in amorphous $\mathrm{Fe}-\mathrm{Zr}$ alloy has also been reported by other researchers. ${ }^{6,7}$

Systematic variations of magnetic ordering temperature $\left(T_{c}\right)$ vs the $\mathrm{Fe}$ concentration for $\mathrm{Fe}-(\mathrm{Co}, \mathrm{Ni}$, or $\mathrm{Cu})-\mathrm{Ti}$ al loys and $F e$-Ti alloys are shown in Fig. 4 . The value of $T_{c}$ is vastly enhanced by substituting either $\mathrm{Co}, \mathrm{Ni}$, or even $\mathrm{Cu}$ for Fe in amorphous Fe-Ti alloy. It is particularly impressive for alloys with low $F e$ contents, where the $a-F_{e} \mathrm{Ti}_{100-x}$ samples with $x<40$ are not ferromagnetic. The most prominent increase is achieved by suhstituting $F e$ with $C o$. The highest $T_{c}$ of $450 \mathrm{~K}$ is observed in $\mathrm{Fe}_{40} \mathrm{Co}_{30} \mathrm{Ti}_{30}$. Additional $\mathrm{Co}$ causes a slight decrease in $T_{c}$. Intermediate increase is realized in Fe-Ni-Ti alloys reflecting a much smaller Ni moment and weaker magnetic exchange interactions. Even nominally nonmagnetic Cu has a sizable effect in increasing the valwes of $T_{c}$ and the Fe moment.

Finally, it may be mentioned that the atomic sizes of $\mathrm{Co}$, $\mathrm{Ni}$, and $\mathrm{Cv}$ are nearly identical. The variation of the average Fe-Fe distance with $x$ should not be appreciably different for amorphous alloys containing $\mathrm{Co}, \mathrm{Ni}$, or $\mathrm{Cu}$ to give rise to the very different magnetic properties of the three alloy series.

In conclusion, we have systematically substituted $\mathrm{Fe}$ by
$\mathrm{Co}, \mathrm{Ni}$, and $\mathrm{Cu}$ in a prototype $\mathrm{a}-\mathrm{Fe} \mathrm{e}_{70} \mathrm{Ti}_{30}$ alloy. $\mathrm{A}$ large enhancement of $T_{c}$ is realized in all three cases as a result of the increased magnetization and, specifically, the increased $\mathrm{Fe}$ moment. The results have demonstrated that the universally depressed magnetism in binary amorphous alloys of Fe with an early transition-metal element can be greatly enhanced by alloying with $\mathrm{Co}, \mathrm{Ni}$, and $\mathrm{Cu}$. 07150.

This work is supported by NSF Grant No. DMR86-

${ }^{3}$ H. Fukamichi, H. Hiroyoshi, T. Kaneko, T. Masumoto, and K. Shirakawa, J. Appl. Phys. 33, 8107 (1982).

${ }^{2}$ S. H. Liou and C. L. Chien, I. Appl. Phys. 55, 1820 (1984).

${ }^{3}$ C. L. Chien, S. H. Liow, B. K. Ha, and K. M. Unruh, J. Appl. Phys. 57, 3539 (1985).

${ }^{4}$ K. M. Unruh and C. L. Chien, Phys. Rev. B 30, 4968 (1984).

${ }^{5} \mathrm{H}$. Miroyoshi and X. Fukamichi, in High Field Magnetism, edited by $M$. Date (North-Holland, Ansterdam, 1983 ).

6P. Deppe, K. Fukimichi, F. S. Li, M. Rosenberg, and M. Sostarich, IEEE Trans. Magn. MAG-20, 1367 (1984).

'S. Ohnuma, K. Shirakawa, M. Nose, and T. Masumoto, IEEE Trans. Magn. MAG-16, 1129 (1984). 